Received: 10 April 2017

Accepted: 20 June 2017

Published online: 24 July 2017

CIENTIFIC REP

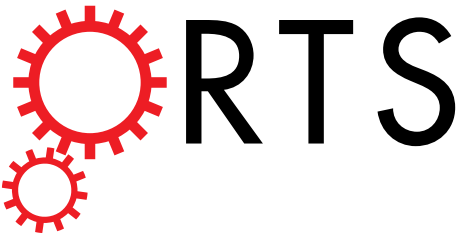

\title{
OPEN
}

\section{Ab Initio Density Functional Calculations and Infra-Red Study of CO Interaction with Pd Atoms on $\theta-\mathrm{Al}_{2} \mathrm{O}_{3}(010)$ Surface}

\author{
Chaitanya K. Narula ${ }^{1}{ }^{1}$, Lawrence F. Allard ${ }^{1}$ \& Zili Wu ${ }^{2}$
}

The $a b$ initio density functional theoretical studies show that energetics favor CO oxidation on single Pd atoms supported on $\theta$-alumina. The diffuse reflectance infra-red spectroscopy (DRIFTS) results show that carbonates are formed as intermediates when single supported Pd atoms are exposed to a gaseous mixture of $\mathrm{CO}+\mathrm{O}_{2}$. The rapid agglomeration of $\mathrm{Pd}$ atoms under $\mathrm{CO}$ oxidation conditions even at $6^{\circ} \mathrm{C}$ leads to the presence of $\mathrm{Pd}$ particles along with single atoms during $\mathrm{CO}$ oxidation experiments. Thus, the observed $\mathrm{CO}$ oxidation has contributions from both single Pd atoms and Pd particles.

The smallest metal "particles" are single supported metal atoms (SACs) which are also present in fresh catalysts and participate in catalytic reactions ${ }^{1-4}$. Among SACs, the single supported palladium appears to be unique in terms of its reactivity for gas phase reactions and organic reactions. For example, Abbet et al. showed that single $\mathrm{Pd}$ atoms supported on an $\mathrm{MgO}$ surface are catalytically active for $\mathrm{CO}$ oxidation ${ }^{5}$. Datye et al. found that single supported Pd atoms on alumina can oxidize CO even at room temperature 6 . Anderson et al., on the other hand, showed that single $\mathrm{Pd}$ atom on titania cannot oxidize $\mathrm{CO}^{7}$. We find that $\mathrm{Pd}$ atoms on alumina are inactive for NO oxidation ${ }^{8}$. Regarding organic reactions, the atomically dispersed Pd(II) sites exhibited exceptional performance for selective oxidation of crotyl alcohol to cinnamaldehyde ${ }^{9}$. Lee et al. showed that the hydrogenation of benzaldehyde over $\mathrm{Pd} 1 / \mathrm{TiO}_{2}$ can be accomplished at room temperature while $\mathrm{Pd} / \mathrm{C}$ is an ineffective catalyst ${ }^{10}$. 1,3-butadienes can be selectively hydrogenated to butenes over Pd1/graphene under mild conditions ${ }^{11}$. The hydrogenation of acetylene on over Pd1/Cu is possible at low conversion (10-20\%) and moderate ethylene selectivity $(30 \%)^{12}$. The highly selective and efficient 1 -hexyne conversion to 1-hexene is possible over [Pd] mpg-C3N $4^{13}$. The hydrogenation of succinic acid to $\gamma$-butyrolactone over atomically dispersed Pd catalyst has been reported but there is some uncertainty on the activity of single atoms since the catalyst is a mix of single atoms and nanoparticles ${ }^{14}$. In contrast, magnetite supported palladium single atoms have been shown to be ineffective for alkene hydrogenation ${ }^{15}$. Thus Pd SACs have high activity for oxidation and hydrogenation type reactions although there are some exceptions.

We have recently shown that inert substrate supported single Pt-atoms ${ }^{16,17}$ are catalytically active for CO and $\mathrm{NO}$ oxidation. In contrast, we found that single supported $\mathrm{Pd}$ atoms are completely ineffective $\mathrm{NO}$ oxidation catalysts ${ }^{8}$. In this manuscript, the $\theta-\mathrm{Al}_{2} \mathrm{O}_{3}$ supported single $\mathrm{Pd}$ atom and $\mathrm{Pd}$ particles are named $\mathrm{Pd}_{\mathrm{s}} / \theta-\mathrm{Al}_{2} \mathrm{O}_{3}$ and $\mathrm{Pd} / \theta-\mathrm{Al}_{2} \mathrm{O}_{3}$, respectively. Intrigued by reports from Anderson et al. ${ }^{7}$ showing lack of activity and Datye et al. ${ }^{6}$ describing room temperature CO oxidation combined with our results on lack of NO oxidation over Pd SACs ${ }^{8}$, we carried out $a b$ initio density functional theoretical studies to gain insights into CO interaction with single supported Pd atoms. We find that energetics of CO oxidation on Pd single atoms are quite favorable regardless of Pd structure (cation or adatom) or alumina involvement. In order to find support for the proposed pathway, we carried out infra-red studies of CO oxidation reactions which show that carbonate intermediates form during $\mathrm{CO}$ oxidation suggesting that our proposed pathway for $\mathrm{CO}$ oxidation on Pd adatom is the most likely pathway. However, we also noticed absorptions assignable to bridging $\mathrm{CO}$ at $6{ }^{\circ} \mathrm{C}$ which suggests that $\mathrm{Pd}$ agglomeration begins even at low temperatures prompting us to repeat $\mathrm{CO}$ oxidation experiments (described in supplementary materials). Unfortunately, our attempts to repeat CO-TPR, reported by Anderson et al. ${ }^{7}$, were not successful since

${ }^{1}$ Materials Science \& Technology Division, Oak Ridge National Laboratory, Oak Ridge, TN, 37831-6133, USA. ${ }^{2}$ Chemical Science Division and Center for Nanophase Materials Sciences, Oak Ridge National Laboratory, Oak Ridge, TN, USA. Correspondence and requests for materials should be addressed to C.K.N. (email: narulack@ornl. gov) 


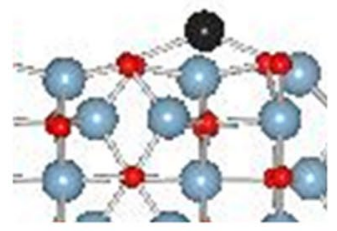

I

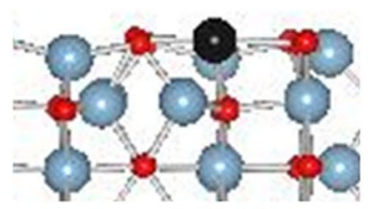

II
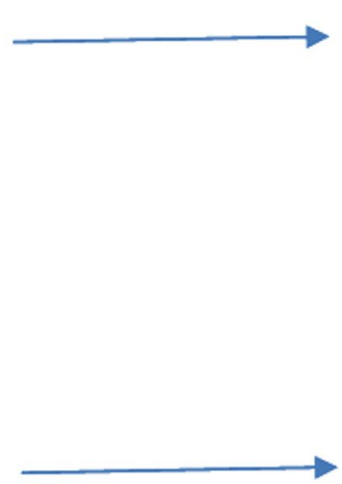

Figure 1. (I). Pd adatom and (II). Pd cation on $\theta$-alumina (010) surface and corresponding oxidized species, (III) and (IV).

we did not have access to a CO-TPR system that could be cooled to $130 \mathrm{~K}$, and the Pd-SACs agglomerated as soon as they were exposed to $\mathrm{CO}$ at room temperature. It is important to point out that Datye et al. also observed agglomeration in their operando $\mathrm{X}$-ray absorption spectroscopic study at $\sim 90^{\circ} \mathrm{C}$ which was not present in their $\mathrm{Pd}$ single atoms dispersed on $\mathrm{La}_{2} \mathrm{O}_{3}-\gamma-\mathrm{Al}_{2} \mathrm{O}_{3}$ substrate. Our experiments show that rapid agglomeration of $\mathrm{Pd}$ atoms occurs even at low temperatures under $\mathrm{CO}$ oxidation conditions. This suggests that the observed CO oxidation has a contribution from agglomerated Pd also.

\section{Results and Discussion}

Proposed pathway for CO oxidation. Density functional theoretical studies for CO oxidation on single atom catalysts in the literature propose two structures for SACs (cation or adatom) and two pathways for CO oxidations ${ }^{1-4}$. The CO oxidation on cationic SACs generally proceeds with CO adsorption on single atoms which react with oxygen from substrate to form $\mathrm{CO}_{2}$ which is then eliminated. The substrate re-oxidizes by capturing oxygen from the reactant stream. The $\mathrm{CO}$ oxidation over adatom SACs proceeds with $\mathrm{CO}$ and oxygen adsorption on single atoms, their rearrangement to $\mathrm{O}-\mathrm{O}-\mathrm{C}=\mathrm{O}$ or carbonate, and release of $\mathrm{CO}_{2}$. The substrate either is not involved in $\mathrm{CO}$ oxidation (e.g. alumina) ${ }^{16,17}$ or participates ${ }^{5}$ by bonding with oxygen (e.g. $\left.\mathrm{MgO}(\mathrm{FC})-\mathrm{Pd}(\mathrm{CO})_{2} \mathrm{O}_{2}\right)$ which is also bonded to single atoms. For CO oxidation on single Pd atoms supported on $\gamma$-alumina, the cationic structure has been proposed and CO oxidation has been proposed to proceed via CO adsorption on Pd atoms which reacts with oxygen from $\gamma$-alumina to form $\mathrm{CO}_{2}{ }^{6}$.

Our recent work ${ }^{8}$ on NO interaction with $\mathrm{Pd}$ atoms supported on $\theta$-alumina shows that Pd adatom, I, is more likely to be formed than Pd cation, II, because the Pd cation is a $\mathrm{d}^{9}$ species that is rare in Pd chemistry [Fig. 1]. Furthermore, the oxidized Pd adatom is more likely to represent Pd SACs since oxidized Pd adatom is tetra-coordinate ${ }^{8}$ which matches well with the reported EXAFS data ${ }^{6}$. Oxidized Pd cation, IV, is a six-coordinate configuration and does not match with the reported EXAFS data.

Here, we present our results on the CO oxidation pathway on an oxidized Pd adatom, III, which is more likely to represent Pd SAC under ambient conditions. The CO oxidation pathway on cationic Pd, II, is presented in Supplementary materials and the results clearly show that CO oxidation is quite facile in cationic Pd also. The rationale for employing $\theta$-alumina instead of $\gamma$-alumina in preparation of model catalyst has been presented previously ${ }^{16,18}$. The proposed pathway for CO oxidation on a Pd adatom proceeds via the scheme shown in Fig. 2. The total energy, Pd bond distances to surface oxygen, and magnetization for all intermediate configurations is summarized in Table 1 . The oxidized configuration III reacts with $\mathrm{CO}$ via an exothermic reaction $(-1.53 \mathrm{eV})$ to form configuration VI. The $\eta 2$ oxygen of configuration III changes to a mono-dentate terminal oxygen in configuration VI. In addition, one of the two Pd-O bonds with surface oxygen breaks to accommodate CO. There is no magnetization associated with configuration VI, and PDOS analysis shows no vacant d-orbitals suggesting a $\mathrm{d}^{10}$ Pd oxidation state [Figure S1].

The carbonate formation (configuration VII) from configuration VI takes place via an exothermic process $(-3.57 \mathrm{eV})$. The carbonate in configuration VII is a bi-dentate ligand and can be considered a 16-electron Pd species. There is no magnetization associated with configuration VII and PDOS does not show vacant d-orbitals, which supports a $\mathrm{d}^{10}$ oxidation state for Pd [Figure S1]. The bidentate bonding of carbonate to Pd is known for 


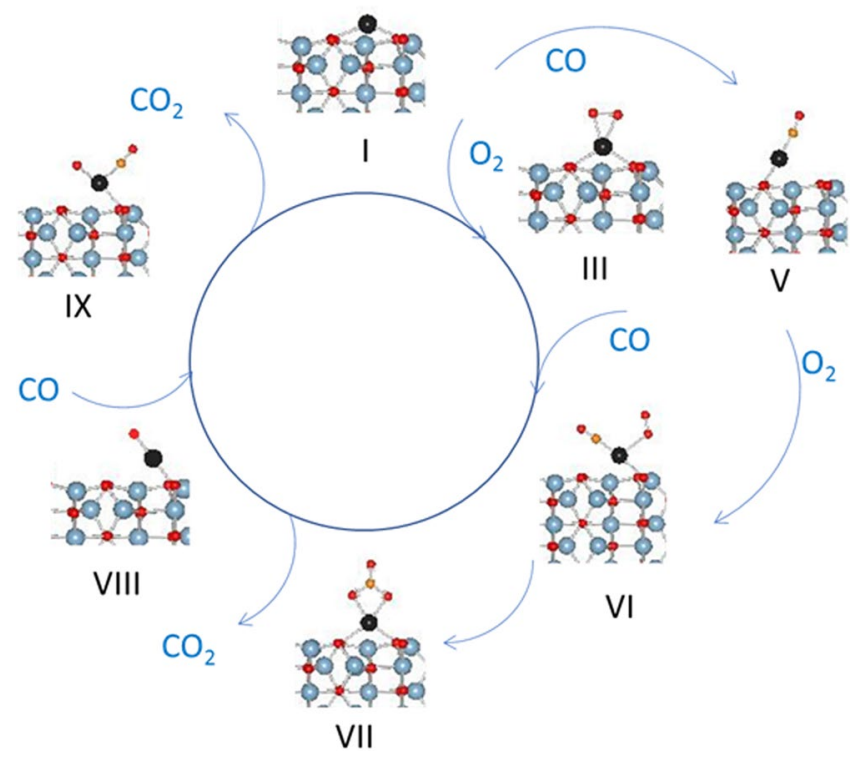

Figure 2. CO oxidation cycle on a single supported Pd adatom.

\begin{tabular}{|c|c|c|c|c|c|c|c|c|}
\hline \multirow[b]{3}{*}{ Configuration } & \multirow[b]{3}{*}{$\Delta E_{I}$} & \multirow{3}{*}{$\begin{array}{l}\text { Total Energy } \\
(\mathrm{eV})\end{array}$} & \multicolumn{2}{|c|}{$\begin{array}{l}\text { Pd-O bonds } \\
(\AA)\end{array}$} & \multicolumn{4}{|c|}{ Magnetic Moment } \\
\hline & & & \multirow[b]{2}{*}{01} & \multirow[b]{2}{*}{$\mathrm{O2}$} & \multirow[t]{2}{*}{$\mu_{\text {Total }}$} & \multirow[t]{2}{*}{$\mu_{\text {Mtotal }}$} & \multicolumn{2}{|c|}{$\mu_{\text {Ototal }}$} \\
\hline & & & & & & & 01 & $\mathrm{O} 2$ \\
\hline I & & -1315.889 & 2.22 & 2.20 & 0.0 & - & - & - \\
\hline III & -10.293 & -1326.182 & 2.27 & 2.24 & 0.0 & - & - & - \\
\hline $\mathrm{V}$ & -16.805 & -1332.694 & - & 2.08 & 0.0 & - & - & - \\
\hline VI & -26.595 & -1342.484 & - & 2.12 & 2.0 & 0.22 & 0.0 & 0.0 \\
\hline VII & -29.640 & -1345.529 & 2.25 & 2.18 & 0.0 & - & - & - \\
\hline ii & -26.869 & -1342.758 & 2.41 & 2.18 & 0.0 & - & - & - \\
\hline VIII & -4.621 & -1320.510 & 2.05 & - & 2.0 & 0.78 & 0.04 & - \\
\hline IX & -20.141 & -1336.030 & - & 2.32 & 0.0 & - & - & - \\
\hline
\end{tabular}

Table 1. Bonding Parameters and Magnetization values of configurations in Fig. $1^{\dagger} .{ }^{\dagger} \mathrm{Pd}$ is bonded to surface oxygen $\mathrm{O} 1$ and $\mathrm{O} 2$. Magnetization spread over other surface atoms is not listed in the table. The data for configurations I are from ref. 18 and III and VIII are from ref. 8.

organopalladium complexes with a Pd-O bond of $2.06 \AA$ and O-C-O angle of $113.5^{\circ}{ }^{19}$. Our optimized Pd-O bond distances are $2.01 \AA$ and O-C-O bond angle is $109.5^{\circ}$.

The three calculated transition states (i-iii) as well as optimized image ii are shown in Fig. 3. The image i optimized to a configuration that is very close to configuration VI in terms of structure and total energy while image iii optimized to a configuration close to configuration VII. The transformation of VI to transition state ii is an endothermic step $(1.48 \mathrm{eV})$ which forms configuration VII via an exothermic step $(-4.045 \mathrm{eV})$.

The loss of $\mathrm{CO}_{2}$ from VII is an endothermic process $(2.06 \mathrm{eV})$ resulting in configuration VII which reacts with $\mathrm{CO}$ via an exothermic process $(-0.73 \mathrm{eV})$ to form configuration VIII. The Pd in configuration VIII is in the $\mathrm{d}^{10}$ oxidation state with no magnetization associated with it. The loss of $\mathrm{CO}_{2}$ via an exothermic process $(-2.82 \mathrm{eV})$ results in the formation of single Pd atom species I. Once the transient species I is formed, it has preference for reaction with $\mathrm{CO}$ over oxygen since its reaction with $\mathrm{CO}$ to form configuration $\mathrm{V}$ is more exothermic than that with molecular oxygen $(-2.03 \mathrm{vs}-1.51 \mathrm{eV})$. Configuration $\mathrm{V}$ is a $\mathrm{d}^{10}$ species with no magnetization associated with it and no empty d orbitals (Figure S1). Configuration V can react with molecular oxygen via an exothermic reaction $(-1.00 \mathrm{eV})$ to form configuration VI.

Another important point to consider is the $\mathrm{O}=\mathrm{C}-\mathrm{O}-\mathrm{O}$ type species which has been proposed as an intermediate in $\mathrm{CO}$ oxidation over $\mathrm{Pt}$ nanoparticles ${ }^{20}$. Since there is only one $\mathrm{Pd}$ atom, the $\mathrm{O}=\mathrm{C}-\mathrm{O}-\mathrm{O}$ species in configuration ii bonds to Pd via carbon and terminal peroxo oxygen [Fig. 4]. The lack of magnetization on Pd and the filled d-orbitals in PDOS suggest a $\mathrm{d}^{10}$ state for Pd. [Figure S1]. The formation ii from configuration VI is and endothermic event but the release of $\mathrm{CO}_{2}$ is an exothermic one. However, the rearrangement of ii to carbonate, VII, is highly exothermic event and is preferred over $\mathrm{CO}_{2}$ release.

The energetics of reactions in Fig. 1 are summarized as follows: 


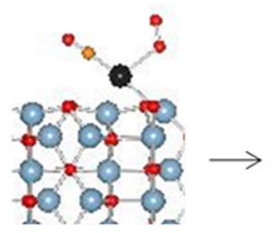

VI

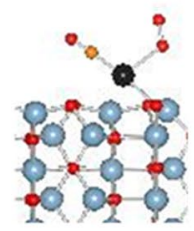

$-1342.4840$

VI

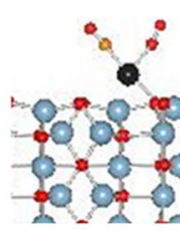

i

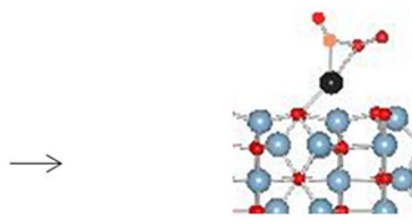

$-1341.0026$

ii

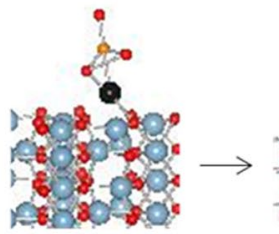

iii

VII

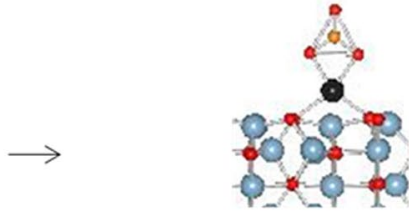

$-1345.5292$

VII

Figure 3. Transition states in carbonate formation over Pd adatom supported on $\theta$-alumina (010) surface.

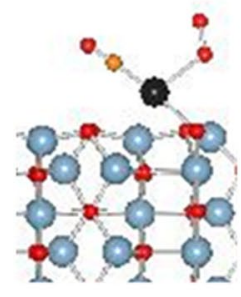

VI

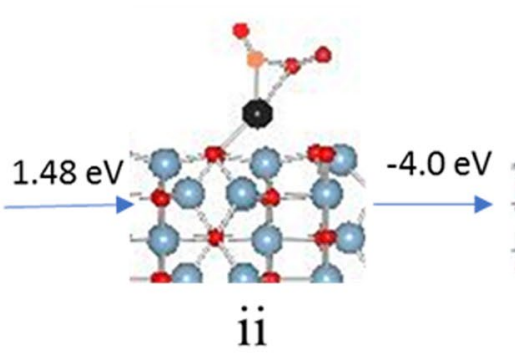

i1

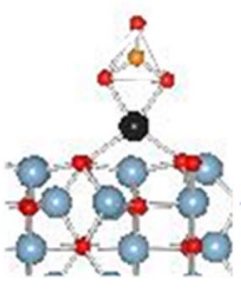

VII

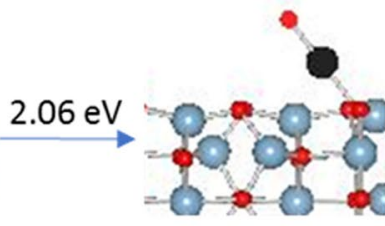

VIII

$-2.46 \mathrm{eV}$

Figure 4. Energetics of $\mathrm{CO}_{2}$ release.

\begin{tabular}{|c|c|c|c|}
\hline$d(I)$ & $+\mathrm{O}_{2}$ & $={ }^{*} \mathrm{PdO}_{2}(\mathrm{III})$ & $-1.51 \mathrm{eV}$ \\
\hline $\mathrm{Pd}(\mathrm{I})$ & $+\mathrm{CO}$ & $={ }^{*} \operatorname{PdCO}(\mathrm{V})$ & $-2.03 \mathrm{eV}$ \\
\hline $\mathrm{PdO}_{2}$ (III) & $-\mathrm{O}$ & $={ }^{*} \mathrm{PdO}(\mathrm{VIII})$ & $5.58 \mathrm{eV}$ \\
\hline * $\mathrm{PdO}_{2}$ (III) & $+\mathrm{CO}$ & $={ }^{*} \mathrm{Pd}\left(\mathrm{O}_{2}\right)(\mathrm{CO})(\mathrm{VI})$ & $-1.526 \mathrm{eV}$ \\
\hline $\mathrm{Pd}\left(\mathrm{O}_{2}\right)(\mathrm{CO})(\mathrm{VI})$ & & $={ }^{*} \mathrm{Pd}\left(\mathrm{CO}_{3}\right)(\mathrm{VII})$ & $-3.57 \mathrm{eV}$ \\
\hline $\mathrm{d}\left(\mathrm{CO}_{3}\right)(\mathrm{VII})$ & $-\mathrm{CO}_{2}$ & $={ }^{*} \mathrm{PdO}(\mathrm{VIII})$ & $2.06 \mathrm{eV}$ \\
\hline $\mathrm{dO}$ (VIII) & $+\mathrm{CO}$ & $={ }^{*} \mathrm{Pd}(\mathrm{O})(\mathrm{CO})(\mathrm{IX})$ & $-0.73 \mathrm{eV}$ \\
\hline$(\mathrm{CO})(\mathrm{IX}$ & $-\mathrm{CO}_{2}$ & $={ }^{*} \mathrm{Pd}(\mathrm{I})$ & $-2.82 \mathrm{eV}$ \\
\hline
\end{tabular}

The pathway suggests that $\mathrm{CO}$ oxidation is feasible on $\mathrm{Pd}$ adatoms and the reaction can proceed either via $\mathrm{O}=\mathrm{C}-\mathrm{O}-\mathrm{O}$ intermediate which form via endothermic reaction from rearrangement of $\mathrm{VI}$ and then releases $\mathrm{CO}_{2}$ via an exothermic reaction or via $\mathrm{CO}_{3}$ intermediate which forms from VI via a highly exothermic reaction and then releases $\mathrm{CO}_{2}$ via an endothermic reaction. The rearrangement of $\mathrm{O}=\mathrm{C}-\mathrm{O}-\mathrm{O}$ to $\mathrm{CO}_{3}$ is also a highly exothermic event. Infra-red studies, described in the next section, provide additional insights into CO interaction with Pd atoms.

In situ Diffuse Reflectance Studies. The catalyst sample $\mathrm{Pds} / \theta-\mathrm{Al}_{2} \mathrm{O}_{3}$ was cleaned under oxidizing conditions employing a mixture of $5 \%$ oxygen in helium. The results of $\mathrm{CO}$ adsorption studies on $\theta$-alumina and $\mathrm{Pds} / \theta$-alumina in the presence of $\mathrm{O}_{2}$ at 6 and $100^{\circ} \mathrm{C}$ are shown in Fig. 5 . We selected $6^{\circ} \mathrm{C}$ because $\mathrm{Pd}_{\mathrm{s}} / \theta-\mathrm{Al}_{2} \mathrm{O}_{3}$ has been shown to oxidize $\mathrm{CO}$ at room temperature and we expected negligible $\mathrm{CO}$ oxidation at this temperature.

Pure $\theta-\mathrm{Al}_{2} \mathrm{O}_{3}$ does not exhibit any $\mathrm{CO}$ adsorption bands which are generally present in $2155-2245 \mathrm{~cm}^{-1}$ and $1050-1090 \mathrm{~cm}^{-1}$ range. The asymmetric and symmetric stretches of bicarbonate are seen at 1650 and $1438 \mathrm{~cm}^{-1}$, respectively. The $\mathrm{Pd}_{\mathrm{s}} / \theta-\mathrm{Al}_{2} \mathrm{O}_{3}$ sample shows bands in $1900-2150 \mathrm{~cm}^{-1}$ region typically associated with adsorbed CO. The bands at 2050, 2085, and $2135 \mathrm{~cm}^{-1}$ can be assigned to linear CO (a-top bound CO on $\mathrm{Pd}^{0}$ and $\mathrm{Pd}^{2+}$ ) 


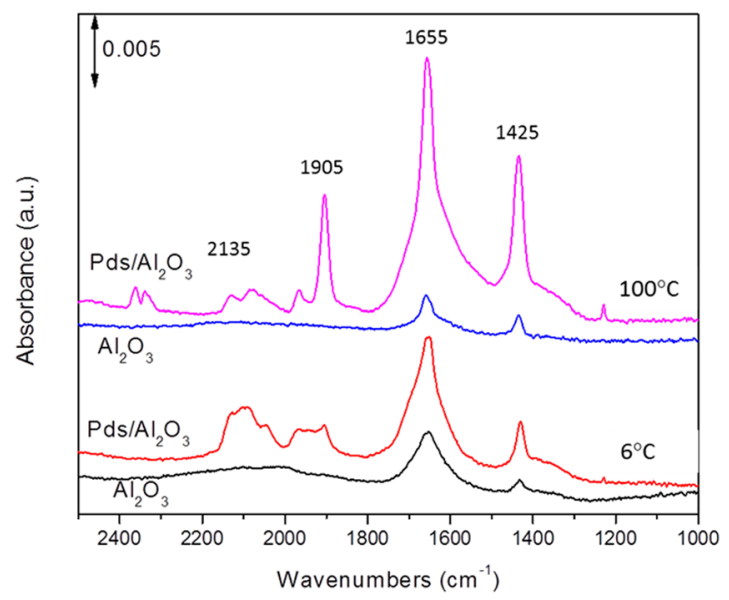

Figure 5. A comparison of in situ IR spectra during $\mathrm{CO}$ oxidation at 6 and $100^{\circ} \mathrm{C}$ on $\theta$-alumina and $\mathrm{Pds} / \theta$ alumina.

while the bands at 1905 and $1970 \mathrm{~cm}^{-1}$ can be assigned to two-fold bridge $\mathrm{CO}^{21}$. This suggests that CO oxidation conditions induce $\mathrm{Pd}$ agglomeration even at $6^{\circ} \mathrm{C}$ since single atoms cannot support bridged $\mathrm{CO}$. The dominant peaks are carbonate peaks at 1655 and $1425 \mathrm{~cm}^{-1}$ which are assigned to bidentate carbonates in comparison with $\mathrm{CO}_{3}$ adsorption bands for organopalladium carbonates since single Pd atoms are isoelectronic with organopalladium carbonates. Several such compounds are known and the position of $v_{\mathrm{s}} \mathrm{C}-\mathrm{O}$ bands of carbonate has been reported to be in $1600-1650 \mathrm{~cm}^{-1}$ range and depending on the organo-species in organopalladium carbonates ${ }^{20,22-24}$. Considering that the position of carbonate bands on $\theta-\mathrm{Al}_{2} \mathrm{O}_{3}$ and $\mathrm{Pd}_{\mathrm{s}} / \theta-\mathrm{Al}_{2} \mathrm{O}_{3}$ is almost identical, the dramatic increase in intensity of carbonate bands on $\mathrm{Pd}_{\mathrm{s}} / \theta-\mathrm{Al}_{2} \mathrm{O}_{3}$ can be allocated to carbonates on $\mathrm{Pd}$. It is important to note that previous detailed work on $\mathrm{CO}$ and $\mathrm{CO}_{2}$ interaction with $\mathrm{Pd} / \gamma-\mathrm{Al}_{2} \mathrm{O}_{3}$ at $22^{\circ} \mathrm{C}$ shows that carbonate and bicarbonate species are primarily due to interaction of $\mathrm{CO}_{2}$ with hydroxyls on alumina surface ${ }^{25,26}$. No carbonates or bicarbonates were observed on the Pd particle surface. In a recent study of CO oxidation over alumina-supported platinum, Newton et al. conclude that the inability of $\theta$-alumina to catalyze CO oxidation coupled with weak bidentate carbonate bands and missing adsorption in $1200-1300 \mathrm{~cm}^{-1}$ suggest that the species on $\theta$-alumina are not a significant factor in $\mathrm{CO}$ oxidation reactions ${ }^{27}$.

Increasing temperatures to $100^{\circ} \mathrm{C}$ for $\mathrm{CO}$ oxidation results in several important changes in the IR of $\mathrm{Pds} / \theta$-alumina. First, two bands associated with physisorbed $\mathrm{CO}_{2}$ can be seen at $2040-2060 \mathrm{~cm}^{-1}$. Second, the carbonate bands at 1655 and $1425 \mathrm{~cm}^{-1}$ become very strong. Finally, there is a dramatic increase in $1905 \mathrm{~cm}^{-1}$ band for bridging $\mathrm{CO}$ bonded to $\mathrm{Pd}$. The presence of physisorbed $\mathrm{CO}_{2}$ and increase in bidentate carbonate intermediate suggests that $\mathrm{CO}$ oxidation has accelerated at $100^{\circ} \mathrm{C}$ which is commensurate with our experimental observations. The formation of Pd nanoclusters leads to increase in bridging $\mathrm{CO}$ bands. The IR of CO adsorption on $\theta$-alumina sample does not change at $100^{\circ} \mathrm{C}$ and is comparable to the one observed at $6^{\circ} \mathrm{C}$ suggesting that the carbonates formed on $\theta$-alumina are stable at $100^{\circ} \mathrm{C}$. The time-resolved IR spectra during adsorption of $\mathrm{CO}+\mathrm{O}_{2}$ for 5 minutes followed by $\mathrm{O}_{2}$ purge for 5 minutes at $6^{\circ} \mathrm{C}$ are shown in Fig. 6 (top).

The fresh oxidized catalyst starts to adsorb $\mathrm{CO}$ in linear mode immediately with simultaneous appearance of carbonate bands. The bridging CO also starts to build up although it is quite week. At five minutes, the linear CO bands and carbonate bands are the strongest bands. Immediately after an $\mathrm{O}_{2}$ purge is started, the linear $\mathrm{CO}$ bands disappear within 30 seconds with concurrent strengthening of the carbonate bands. No physisorbed $\mathrm{CO}_{2}$ bands are observed in either $\mathrm{CO}$ or $\mathrm{O}_{2}$ pulse cycle. Increasing the temperature to $100^{\circ} \mathrm{C}$ (bottom of Fig. 6) results in immediate appearance of physisorbed $\mathrm{CO}_{2}$ bands which continue to become weak during $\mathrm{CO}+\mathrm{O}_{2}$ reaction and become very weak during the $\mathrm{O}_{2}$ purge. A similar trend is found for the carbonate IR peaks which are initially strong but start to decrease due to the loss of $\mathrm{CO}_{2}$ and continue to decrease in the $\mathrm{O}_{2}$ cycle. The linear $\mathrm{CO}$ peaks on single $\mathrm{Pd}$ atoms practically disappear as soon as the $\mathrm{O}_{2}$ cycle begins but the CO peaks on $\mathrm{Pd}$ nanoparticles take almost 2 minutes under $\mathrm{O}_{2}$ to become weaker. The bridging $\mathrm{CO}$ band increases in $\mathrm{CO}+\mathrm{O}_{2}$ cycle and does not change after 2 minutes in the $\mathrm{O}_{2}$ cycle.

The observation of carbonate at $6^{\circ} \mathrm{C}$ in a $\mathrm{CO}+\mathrm{O}_{2}$ cycle which does not decrease in the $\mathrm{O}_{2}$ cycle, and lack of $\mathrm{CO}_{2}$ release supports our proposed mechanism which shows that the decomposition of carbonate is endothermic and the $\mathrm{CO}$ oxidation will stop after the catalyst surface is covered with carbonate species. At $100^{\circ} \mathrm{C}$, the release of $\mathrm{CO}_{2}$ is observed which is commensurate with our experimental observation that CO oxidation on Pds/ $\theta$-alumina begins just above $100^{\circ} \mathrm{C}$ (Fig. 2). Our experiments also show that the agglomeration of Pd single atoms begins immediately under $\mathrm{CO}$ oxidation conditions at $6^{\circ} \mathrm{C}$ but is very slow. This agglomeration accelerates at $100^{\circ} \mathrm{C}$ resulting in particles that adsorb $\mathrm{CO}$ in the bridging mode.

CO oxidation on single supported Pd atoms. In literature, the first report on CO oxidation catalyzed by isolated Pd atoms appeared in 2001. Abbet et al. showed that Pd atoms anchored on oxygen surface vacancies of $\mathrm{MgO}(100)$ thin films when exposed to oxygen followed by $\mathrm{CO}$ release $\mathrm{CO}_{2}$ with desorption at 260 and $500 \mathrm{~K}$. Abbet el al. also showed that if the sequence is reversed i.e. if $\mathrm{CO}$ is adsorbed first before oxygen, $\mathrm{CO}_{2}$ formation is suppressed due to $\mathrm{CO}$ poisoning. Anderson et al., on the other hand, found no $\mathrm{CO}$ oxidation on $\mathrm{Pd}_{1} / \mathrm{TiO}_{2}$ in 

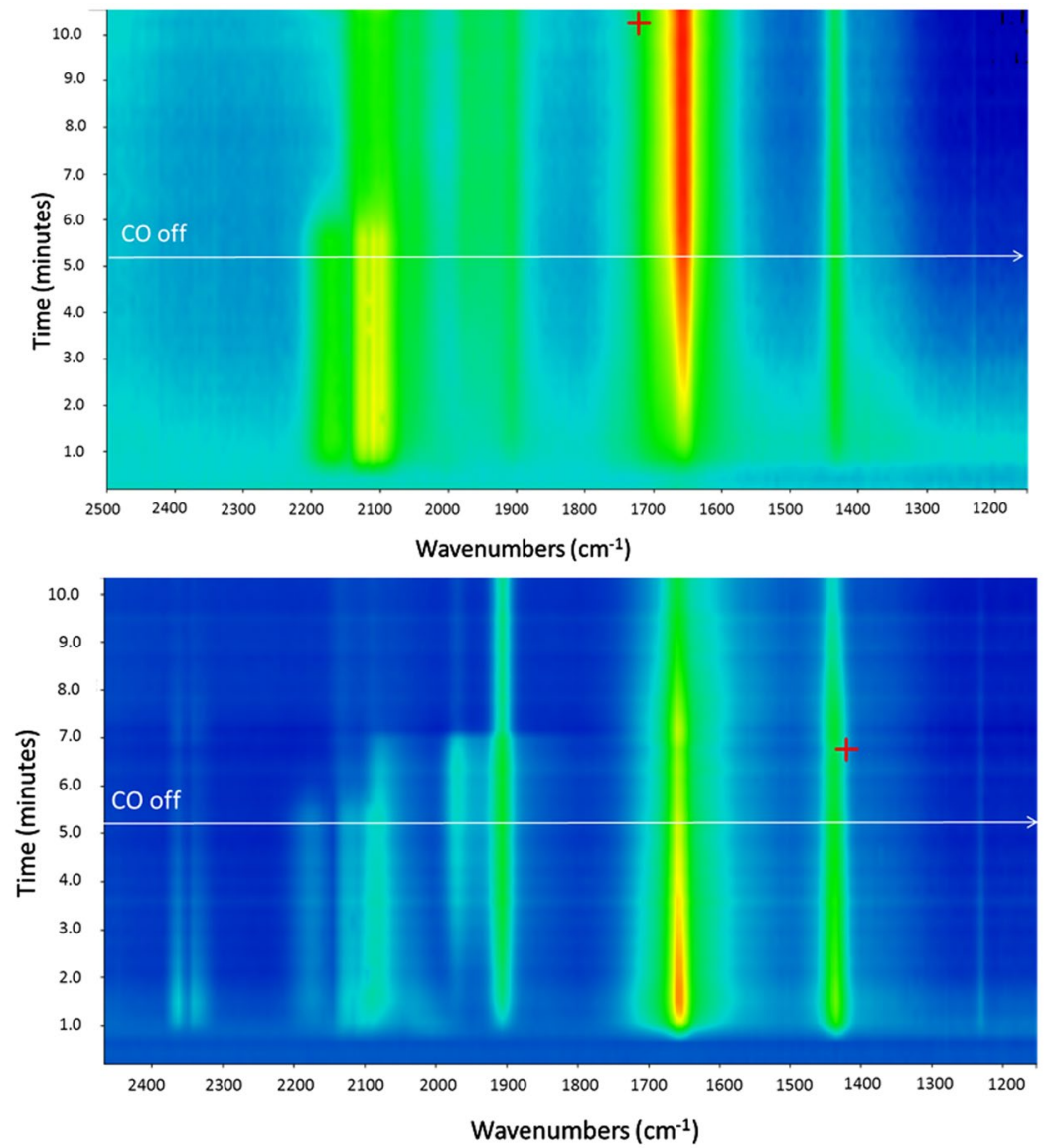

Figure 6. The evolution of IR bands during adsorption of $\mathrm{CO}+\mathrm{O}_{2}$ for 5 minutes followed by desorption in $\mathrm{O}_{2}$ flow for 5 minutes at $6^{\circ} \mathrm{C}$ (top) and $100^{\circ} \mathrm{C}$ (bottom).

their TPR experiments in the -143 to $257^{\circ} \mathrm{C}$ range, after treatment of $\mathrm{Pd} 1 / \mathrm{TiO}_{2}$ samples with $\mathrm{O}_{2}$ at $127^{\circ} \mathrm{C}$ and $\mathrm{CO}$ at $-93^{\circ} \mathrm{C}^{7}$. A definitive work from Datye et al. found that $\mathrm{CO}$ oxidation is quite facile on single Pd atoms. The kinetic studies show that the reaction order for single $\mathrm{Pd}$ is -0.2 for $\mathrm{CO}$ and +0.16 for $\mathrm{O}_{2}$ which changes to -1 for $\mathrm{CO}$ and +1 for $\mathrm{O}_{2}$ as single $\mathrm{Pd}$ atom agglomerate to $\mathrm{Pd}$ metal $^{6}$. The strongest evidence for the activity of $\mathrm{Pd}$ comes from the operando XAS study of single $\mathrm{Pd}$ atoms supported on $\mathrm{La}_{2} \mathrm{O}_{3}-\gamma-\mathrm{Al}_{2} \mathrm{O}_{3}$ which clearly show that $\mathrm{Pd}-\mathrm{Pd}$ bonds are not present in the fresh sample or after exposure to $\mathrm{CO}$ oxidation conditions in the temperature range of $40-90^{\circ} \mathrm{C}$.

Our theoretical studies show that oxidized $\mathrm{Pd}$ adatom is likely representative of $\mathrm{Pd}_{\mathrm{s}} / \theta-\mathrm{Al}_{2} \mathrm{O}_{3}$ and energetics favor $\mathrm{CO}$ oxidation. This pathway suggests that $\mathrm{CO}$ oxidation proceeds via carbonate $($ or $\mathrm{O}-\mathrm{O}-\mathrm{C}=\mathrm{O})$ intermediate. This is different from our previous finding that $\mathrm{NO}$ oxidation is not facile since there was no driving force to form $\mathrm{O}=\mathrm{N}-\mathrm{O}-\mathrm{O}$ or nitrate intermediates ${ }^{8}$. The infra-red studies show that carbonate intermediates are indeed formed under $\mathrm{CO}$ oxidation conditions on $\mathrm{Pd}_{\mathrm{s}} / \theta-\mathrm{Al}_{2} \mathrm{O}_{3}$. However, we noticed the $\mathrm{Pd}$ atoms start to agglomerate at temperatures as low as $6^{\circ} \mathrm{C}$ under $\mathrm{CO}$ oxidation conditions. This led us to repeat parts of the experiments, described by Anderson et al. and Datye et al., and the results are described in the Supplementary section. First, we attempted TPR experiment by flowing air over $\mathrm{Pd}_{\mathrm{s}} / \theta-\mathrm{Al}_{2} \mathrm{O}_{3}$ at $25^{\circ} \mathrm{C}$ and then switched the gas to $\mathrm{CO}$ which resulted in instantaneous graying of the sample. After 30 minutes of $\mathrm{CO}$ flow, the reaction was stopped and sample examined by electron microscopy which showed that the sample contained primarily large Pd particles. Second, we carried out $\mathrm{CO}$ oxidation over $\mathrm{Pd}_{\mathrm{s}} / \theta-\mathrm{Al}_{2} \mathrm{O}_{3}$ and $\mathrm{Pd} / \theta-\mathrm{Al}_{2} \mathrm{O}_{3}$ and found both catalysts to be quite effective. Electron microscopy of samples after $\mathrm{CO}$ oxidation also showed extensive agglomeration of $\mathrm{Pd}$ atoms.

Thus, theoretical studies suggest that $\mathrm{Pd}_{\mathrm{s}} / \theta-\mathrm{Al}_{2} \mathrm{O}_{3}$ can be effective $\mathrm{CO}$ oxidation catalysts. But, the experimental work does not confirm the activity of $\mathrm{Pd}_{s} / \theta-\mathrm{Al}_{2} \mathrm{O}_{3}$ because $\mathrm{Pd}$ agglomerates form as soon as the sample is exposed to $\mathrm{CO}$ oxidation conditions. In view of previous work by Datye et al. on CO oxidation activity of Pd atoms, we conclude that observed $\mathrm{CO}$ oxidation has contributions from both single atoms and particles formed from agglomeration of Pd atoms.

\section{Methods}

The $\theta-\mathrm{Al}_{2} \mathrm{O}_{3}$ supported single $\mathrm{Pd}$ atom and $\mathrm{Pd}$ particles are named $\mathrm{Pd}_{\mathrm{s}} / \theta-\mathrm{Al}_{2} \mathrm{O}_{3}$ and $\mathrm{Pd} / \theta-\mathrm{Al}_{2} \mathrm{O}_{3}$, respectively and their synthesis and characterization has been presented in a recent publication. 
Computational Method. The total energy calculations, based on ab initio DFT, were carried out employing the Vienna Ab Initio Simulation Package (VASP) ${ }^{28}$. A generalized gradient approximation (GGA) in the Perdew-Wang-91 form was employed for the electron exchange and correlation potential ${ }^{29,30}$. The projector-augmented wave (PAW) approach for describing electronic core states was used to solve Kohn-Sham equations ${ }^{31,32}$. The plane wave basis set was truncated at a kinetic energy cutoff of $500 \mathrm{eV}$. A Gaussian smearing function with a width of $0.05 \mathrm{eV}$ was applied near Fermi levels. Ionic relaxations were considered converged when the forces on the ions were $>0.03 \mathrm{eV} / \AA$. We have previously described the details of construction of $(010)$ alumina surface ${ }^{18}$. From bulk optimized $\theta$-alumina, a 180 atom charge neutral $2 \times 4$ supercell was constructed ${ }^{18}$. The slabs were separated by a $15 \AA$ vacuum to minimize spurious interaction by periodic images. A $4 \times 1 \times 4$ Monkhorst-Pack mesh was used for surface calculations. Nudged elastic band method was employed to find transition states ${ }^{33,34}$

Infrared Study during CO Adsorption. The detailed methods for CO oxidation by in situ diffuse reflectance Fourier transform infrared spectroscopy (DRIFTS) have been described previously ${ }^{16}$. In summary, a Nicolet Nexus 670 spectrometer fitted with a MCT detector cooled with liquid nitrogen was used for recording spectra. The system is equipped with an in situ chamber (HC-900, Pike Technologies) with a capability to heat samples to $900^{\circ} \mathrm{C}$. For CO oxidation study, all samples were first cleaned by heating to $150^{\circ} \mathrm{C}$ under a flow of $25 \mathrm{~mL} / \mathrm{min} 5 \%$ $\mathrm{O}_{2}$ in helium at a rate of $3^{\circ} \mathrm{C} / \mathrm{min}$ with a hold time of $1 \mathrm{~h}$. The $\mathrm{CO}$ adsorption spectra were recorded after exposing the samples to $12.5 \mathrm{~mL} / \mathrm{min} 2 \% \mathrm{CO} / 2 \% \mathrm{Ar} / \mathrm{He}$ plus $12.5 \mathrm{~mL} / \mathrm{min} 5 \% \mathrm{O}_{2} / \mathrm{He}$ for about 5 minutes and flushing the sample with $5 \% \mathrm{O}_{2} / \mathrm{He}(25 \mathrm{~mL} / \mathrm{min})$ at 6 and $100^{\circ} \mathrm{C}$.

\section{References}

1. Yang, X.-F. et al. Single-Atom Catalysts: A New Frontier in Heterogeneous Catalysis. Acc. Chem. Res. 46, 1740-1748 (2013).

2. Narula, C. K., DeBusk, M. M. Catalysis on Single Supported Atoms in "Catalysis by Materials with Well- Defined Structure" (ed. Overbury, S. J., Wu, Z. Academic Press, New York, pp 263, 2015).

3. Liang, S. X., Hao, C. \& Shi, Y. T. The Power of Single Atom Catalysis. ChemCatChem 7, 2559-2567 (2015).

4. Liu, J. Y. Catalysis by Supported Single Metal Atoms. ACS Catal. 7, 34-59 (2017).

5. Abbet, S., Heiz, U., Hakkinen, H. \& Landman, U. CO Oxidation on a Single Pd Atom Supported on Magnesia. Phys. Rev. Lett. 86, 5950 (2001).

6. Peterson, E. J. et al. Low-temperature carbon monoxide oxidation catalyzed by regenerable atomically dispersed palladium on alumina. Nat. Commun. 5, 4885 (2014).

7. Kaden, W. E., Wu, T., Kunkel, W. A. \& Anderson, S. L. Electronic Structure Controls Reactivity of Size-Selected Pd Clusters Adsorbed on $\mathrm{TiO}_{2}$ Surfaces. Science 326, 826 (2009).

8. Narula, C. K., Allard, L. F., DeBusk, M. M., Stocks, G. M. \& Wu, Z. Single Pd Atoms on $\theta-\mathrm{Al}_{2} \mathrm{O}_{3}(010)$ Surface do not Catalyze NO Oxidation. Sci. Rep. 7, 560 (2017).

9. Hackett, S. F. J. et al. High-Activity, Single-Site Mesoporous $\mathrm{Pd} / \mathrm{Al}_{2} \mathrm{O}_{3}$ Catalysts for Selective Aerobic Oxidation of Allylic Alcohols. Angew. Chem. Int. Ed. 46, 8593-8596 (2007).

10. Liu, P. X. et al. Photochemical Route for Synthesizing Atomically Dispersed Palladium Catalysts. Science. 352, 797-801 (2016).

11. Luci, F. R. et al. Selective hydrogenation of 1,3-butadiene on platinum-copper alloys at the single-atom limit. Nat. Commun. 6, 8550 (2015).

12. Kyriakou, G. et al. Isolated Metal Atom Geometries as a Strategy for Selective Heterogeneous Hydrogenations. Science 335, 1209 (2012).

13. Vile, G. et al. A Stable Single-Site Palladium Catalyst for Hydrogenations. Angew. Chem. Int. Ed. 54, 11265-11269 (2015).

14. Zhang, C., Chen, L., Cheng, H., Zhu, X. \& Qi, Z. Atomically dispersed Pd catalysts for the selective hydrogenation of succinic acid to $\gamma$-butyrolactone. Catal. Today 276, 55-61 (2016).

15. Rossell, M. D. et al. Magnetite-supported palladium single-atoms do not catalyse the hydrogenation of alkenes but small clusters do. Catal. Sci. Techol. 6, 4081 (2016)

16. Moses-DeBusk, M. et al. CO Oxidation on Supported Single Pt Atoms: Experimental and ab initio Density Functional Studies of CO Interaction with Pt Atom on $\theta-\mathrm{Al}_{2} \mathrm{O}_{3}$ (010). J. Am. Chem. Soc. 135, 12634-12645 (2013).

17. Narula, C. K., Allard, L. F., Stocks, G. M. \& DeBusk, M. M. Remarkable NO Oxidation on Single Supported Platinum Atoms. Sci. Rep. 4, 7238 (2014).

18. Narula, C. K. \& Stocks, G. M. Ab Initio Density Functional Calculations of Adsorption of Transition $\mathrm{Metal}_{\mathrm{Atoms}}$ on $\theta-\mathrm{Al}_{2} \mathrm{O}_{3}(010)$ Surface. J. Phys. Chem. C 116, 5628 (2012).

19. Adjabeng, G. et al. Palladium Complexes of 1,3,5,7-Tetramethyl-2,4,8-trioxa-6-phenyl-6-phosphaadamantane: Synthesis, Crystal Structure and Use in the Suzuki and Sonogashira Reactions and the $\alpha$-Arylation of Ketones. J. Org. Chem. 69, 5082 (2004).

20. Allian, A. D. et al. Chemisorption of CO and Mechanism of CO Oxidation on Supported Platinum Nanoclusters. J. Am. Chem. Soc. 133, 4498 (2011).

21. Stahl, S. S., Thorman, J. L., Nelson, R. C. \& Kozee, M. A. Oxygenation of Nitrogen-Coordinated Palladium(0): Synthetic, Structural, and Mechanistic Studies and Implications for Aerobic Oxidation Catalysis. J Am. Chem Soc. 123, 7188 (2001).

22. Ariyananda, P. W. G., Yap, G. P. A. \& Rosenthal, J. Reaction of Carbon Dioxide with a Palladium-Alkyl Complex Supported by a bis-NHC Framework. Dalton Trans. 41, 7977-7983 (2012).

23. Campora, J., Palma, P., del Rio, D. \& Carmona, E. Nitrosyl, Nitro, and Nitrato Complexes of Palladium (IV). The First Structurally Characterized Mononuclear Nitrosyl Complex of Palladium. Organometallics 22, 345-3347 (2003).

24. Stromnova, T. A. et al. Trinuclear palladium complexes containing terminal nitrosyl ligands: Behavior in solid state and in solution. $\mathrm{X}$-ray structures of $\mathrm{Pd}_{3}(\mathrm{NO})_{2}\left(\mu-\mathrm{OCOCX}_{3}\right)_{4}(\eta 2-\mathrm{ArH})_{2}(\mathrm{X}=\mathrm{F}, \mathrm{Cl} ; \mathrm{ArH}=$ toluene or benzene). Inorg. Chim. Acta 359, 1613 (2006).

25. Szanyi, J. \& Kwak, J. H. Dissecting the steps of $\mathrm{CO}_{2}$ reduction: 1 . The interaction of $\mathrm{CO}$ and $\mathrm{CO} 2$ with $\gamma-\mathrm{Al}_{2} \mathrm{O}_{3}$ : an in situ FTIR study. Phys. Chem. Chem. Phys. 16, 15126 (2014)

26. Szanyi, J. \& Kwak, J. H. Dissecting the steps of $\mathrm{CO}_{2}$ reduction: 2 . The interaction of $\mathrm{CO}$ and CO 2 with $\mathrm{Pd} / \gamma-\mathrm{Al}_{2} \mathrm{O}_{3}$ : an in situ FTIR study. Phys. Chem. Chem. Phys. 16,15126 (2014)

27. Newton, M. A., Ferri, D., Smolentsev, G., Marchionni, V. \& Nachtegaal, M. Room-temperature carbon monoxide oxidation by oxygen over $\mathrm{Pt} / \mathrm{Al}_{2} \mathrm{O}_{3}$ mediated by reactive platinum carbonates. Nat. Comm. 6, 8765 (2015).

28. Kresse, G. \& Furthmuller, J. Efficiency of ab-initio total energy calculations for metals and semiconductors using a plane-wave basis set. Comput. Mater. Sci. 6, 15-50 (1996).

29. Kresse, G. \& Joubert, D. From ultrasoft pseudopotentials to the projector augmented-wave method. Phys. Rev. B 59, 1758-1775 (1999).

30. Blochl, P. E. Projector augmented-wave method. Phys. Rev. B 50, 17953-17979 (1994). 
31. Perdew, J. P. \& Wang, Y. Accurate and simple analytic representation of the electron-gas correlation energy. Phys. Rev. B 45, 13244-13249 (1992).

32. Perdew, J. P. et al. Atoms, molecules, solids, and surfaces: Applications of the generalized gradient approximation for exchange and correlation. Phys. Rev. B 46, 6671-6687 (1992).

33. Mills, G., Jonsson, H. \& Schenter, G. K. Reversible work transition state theory: application to dissociative adsorption of hydrogen. Surface Science 324, 305 (1995).

34. Jonsson, H.; Mills, G.; Jacobsen, K. W. Nudged Elastic Band Method for Finding Minimum Energy Paths of Transitions in 'Classical and Quantum Dynamics in Condensed Phase Simulations', ed. B. J. Berne, G. Ciccotti and D. F. Coker (World Scientific, 1998).

\section{Acknowledgements}

The research was sponsored by the U.S. Department of Energy, Office of Energy Efficiency and Renewable Energy, Vehicle Technologies Office, Propulsion Materials Program (C.K.N, L.F.A.) under contract DE-AC05-ooOR22725 with UT-Battelle, LLC. Z.W. was supported by the U.S. Department of Energy, Office of Science, Basic Energy Sciences, Chemical Sciences, Geosciences, and Biosciences Division. The in-situ IR work was conducted at the Center for Nanophase Materials Sciences, which is a DOE Office of Science User Facility.

\section{Author Contributions}

All authors reviewed the manuscript and gave approval to the final version of the manuscript. C.N. carried out most of the experimental work, theoretical modelling work, and wrote the manuscript. L.F.A. provided aberration-corrected electron micrographs and Z.W. obtained DRIFTS data on the atomically dispersed Pd under $\mathrm{CO}$ oxidation conditions, both co-authors reviewed and edited the manuscript.

\section{Additional Information \\ Supplementary information accompanies this paper at doi:10.1038/s41598-017-06405-7}

Competing Interests: The authors declare that they have no competing interests.

Publisher's note: Springer Nature remains neutral with regard to jurisdictional claims in published maps and institutional affiliations.

Open Access This article is licensed under a Creative Commons Attribution 4.0 International License, which permits use, sharing, adaptation, distribution and reproduction in any medium or format, as long as you give appropriate credit to the original author(s) and the source, provide a link to the Creative Commons license, and indicate if changes were made. The images or other third party material in this article are included in the article's Creative Commons license, unless indicated otherwise in a credit line to the material. If material is not included in the article's Creative Commons license and your intended use is not permitted by statutory regulation or exceeds the permitted use, you will need to obtain permission directly from the copyright holder. To view a copy of this license, visit http://creativecommons.org/licenses/by/4.0/.

(c) The Author(s) 2017 